\title{
Bell's Palsy as a Late Neurologic Manifestation of COVID-19 Infection
}

\author{
Ibiyemi O. Oke ${ }^{1}$, Olubunmi O. Oladunjoye ${ }^{1}$, Adeolu O. Oladunjoye ${ }^{2,3}$, Anish Paudel ${ }^{1}$, Ryan Zimmerman \\ 4
}

1. Internal Medicine, Reading Hospital - Tower Health, West Reading, USA 2. Medical Critical Care, Boston Children's Hospital, Boston, USA 3. Psychiatry, Reading Hospital - Tower Health, West Reading, USA 4. Internal Medicine, Reading Hospital - Tower health, West Reading, USA

Corresponding author: Ibiyemi O. Oke, ibiyemioke@yahoo.com

\begin{abstract}
Bell's palsy is acute peripheral facial nerve palsy; its cause is often unknown but it can be triggered by acute viral infection. Coronavirus disease 2019 (COVID-19) infection commonly presents with respiratory symptoms, but neurologic complications have been reported. A few studies have reported the occurrence of facial nerve palsy during the COVID-19 pandemic. We present a case of Bell's palsy in a 36-year-old man with COVID-19 infection and a past medical history of nephrolithiasis. He presented to the emergency room with a day history of sudden right facial weakness and difficulty closing his right eye four weeks following a diagnosis of COVID-19 infection. Physical examination revealed right lower motor neuron facial nerve palsy (House-Brackmann grade IV). Serologic screen for Lyme disease, human immunodeficiency virus (HIV), and herpes simplex virus (HSV) 1 and 2 were negative for acute infection; however, neuroimaging with MRI confirmed Bell's palsy. He made remarkable improvement following treatment with a course of valacyclovir and methylprednisolone. This case adds to the growing body of literature on neurological complications that should be considered when managing patients with COVID-19 infection.
\end{abstract}

Categories: Internal Medicine, Neurology, Infectious Disease

Keywords: bell's palsy, covid-19 infection, facial weakness, neurologic manifestation

\section{Introduction}

Bell's palsy is an acute peripheral lower motor neuron (LMN) facial nerve palsy leading to weakness on one side of the face without any other neurologic abnormalities on examination. The cause is often unknown; however, herpes simplex virus isoform 1 (HSV 1) and/or herpes zoster virus (HZV) reactivation is thought to be the most likely cause [1]. Severe acute respiratory syndrome coronavirus 2 (SARS-CoV-2) is the novel virus that causes coronavirus disease 2019 (COVID-19). It was first identified in Wuhan, a city in Hubei province of China, in December 2019.

Review began 03/08/2021 Review ended 03/12/2021 Published 03/14/2021

\section{(๑) Copyright 2021}

Oke et al. This is an open access article distributed under the terms of the Creative Commons Attribution License CC-BY 4.0., which permits unrestricted use, distribution, and reproduction in any medium, provided the original author and source are credited.
There are a few theories on the neuropathogenesis of COVID-19, which include the binding of coronavirus to angiotensin-converting enzyme 2 (ACE2) receptors, which are widely distributed on glial cells and neurons $[2,3]$. Dubé et al. postulated in their study with animal models that there is axonal transport of human coronavirus ( $\mathrm{HCoV}) \mathrm{OC} 43$ protein into the nervous system [4]. These two mechanisms may lead to nerve damage through direct injury, autoimmunity, and ischemia of the vasa nervorum or inflammatory demyelination $[5,6]$.

Facial nerve palsy may be the first presentation of COVID-19 and it may occur within a few days of its diagnosis [7-13]. We present a patient with a unilateral LMN facial nerve palsy four weeks after a diagnosis of COVID-19 infection.

\section{Case Presentation}

A 36-year-old man with a past medical history of nephrolithiasis presented to the emergency room with a day history of sudden right facial weakness and difficulty closing his right eye four weeks following a diagnosis of COVID-19 infection. He had no other neurologic symptoms and no reports of earache, rash, flu-like symptoms, or recent cold sore. He had fever and body aches when he was tested for COVID- 19, which resolved after a few days of treatment with acetaminophen. He denied cough, shortness of breath, or fatigue, and his last chest radiograph was unremarkable. His vital signs on admission were as follows: heart rate of 75 beats/min, blood pressure of $134 / 97 \mathrm{mmHg}$, respiratory rate of 11 breaths/min, and temperature of 36.8oC. Physical examination revealed right LMN facial nerve palsy (House-Brackmann grade IV), but no vesicles or scabs were seen around the external ear and he had no oral ulcers. Laboratory tests showed normal complete blood count and basic metabolic panel, non-reactive human immunodeficiency virus (HIV) 1 and 2, negative herpes simplex virus (HSV) 2 immunoglobulin G (IgG), positive HSV 1 IgG, negative HSV immunoglobulin M (IgM), and Lyme IgG/IgM antibody. He was not retested for COVID-19. Computed tomography (CT) of the brain was negative for stroke or any other intracranial abnormality. Magnetic resonance imaging (MRI) brain showed asymmetric enhancement of the right facial nerve consistent with 


\section{Cureus}

Bell's palsy (Figure 1).

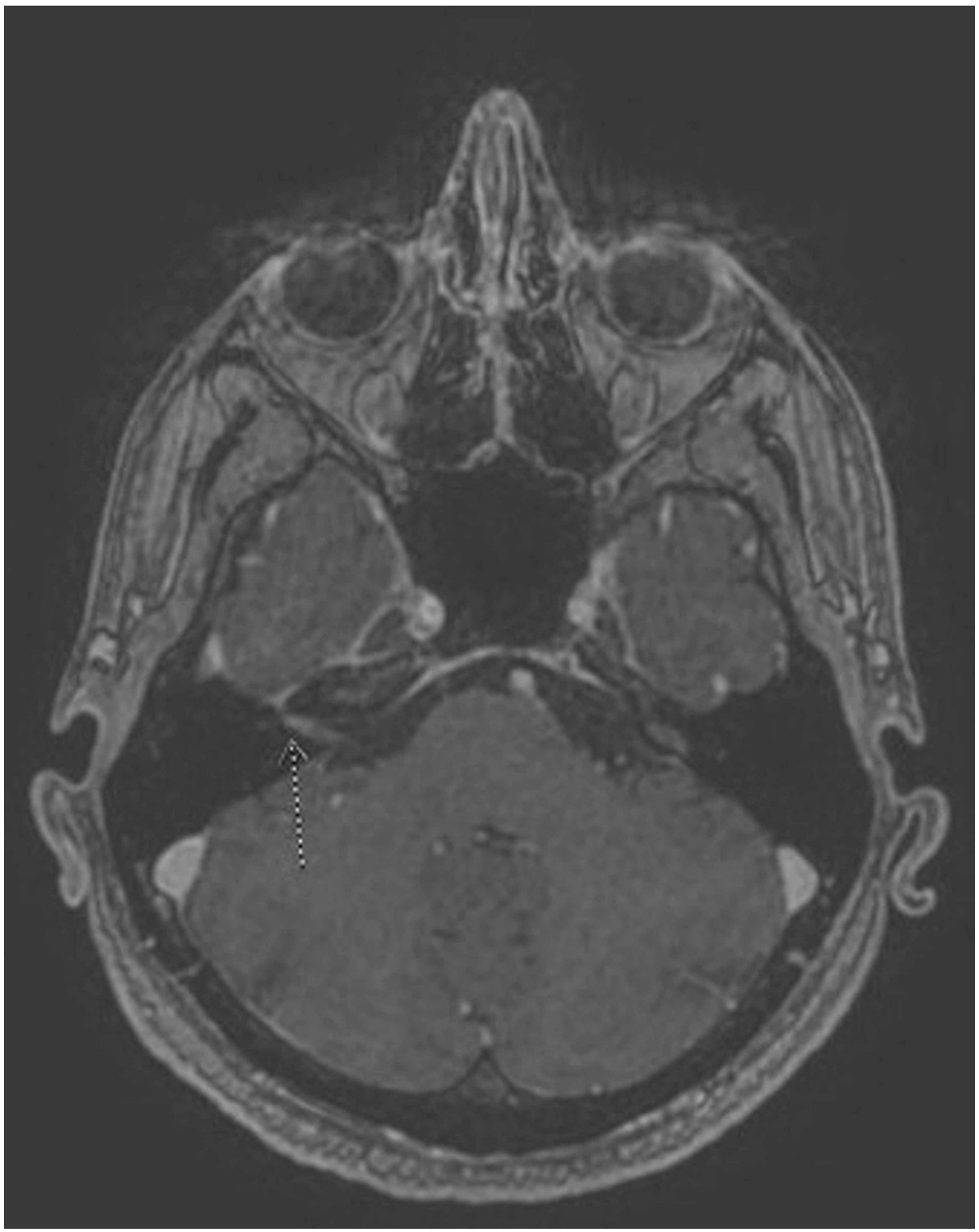

FIGURE 1: Magnetic resonance imaging (MRI) of the brain

Arrow shows asymmetric enhancement of the right facial nerve

A diagnosis of Bell's palsy was made, and he was discharged on a seven-day course of oral valacyclovir 1,000 $\mathrm{mg}$ twice daily and a tapering dose of methylprednisolone ( $24 \mathrm{mg}$ on day $1,20 \mathrm{mg}$ on day $2,16 \mathrm{mg}$ on day 3 , $12 \mathrm{mg}$ on day $4,8 \mathrm{mg}$ on day 5 , and $4 \mathrm{mg}$ on day 6 ). He was provided with eye patch and artificial tears. At three-month follow-up, he reported significant improvement in symptoms and he had only mild right facial nerve weakness (House-Brackmann grade II) on examination.

\section{Discussion}

COVID-19 infection presents mostly with fever and pulmonary symptoms, which could range from mild cough to acute respiratory distress syndrome (ARDS) [14]. Notable complications and causes of death in these patients include sepsis, acute kidney injury, ARDS, acute hypoxic encephalopathy, and acute cardiac injury [14].

Increasing number of COVID-19 related facial nerve palsies are now being reported, with most being the first presenting symptom or occurring within the first week of onset of viral symptoms or a positive COVID-19 test [7-13]. This is a rare case of facial nerve palsy presenting three weeks after resolution of viral symptoms and four weeks after a positive COVID-19 reverse-transcription polymerase chain reaction (RT-PCR) test. 
Over the past year, we have come to know that COVID-19 may also present with neurologic complications such as anosmia, dysgeusia, encephalopathy, Guillain-Barre syndrome, Miller-Fisher syndrome, and polyneuritis cranialis [14-17]. Like this 36-year-old patient, Bell's palsy and CoV is predominantly seen in adults and is often unilateral. Theophanous et al. reported a case in a six-year-old child [9] and Khaja et al. documented a rare case of COVID- 19 and bilateral facial palsy [18]. Although this patient had a positive HSV1 IgG antibody, his IgM antibody was negative and he had no HSV viral exanthem. It still remains unknown if there is a relationship between COVID-19 infection and reactivation of HSV infection leading to Bell's palsy.

The standard treatment of Bell's palsy is steroid with or without antiviral, and this has proven to be effective [19]. A large review by Peitersen et al. shows that $85 \%$ of patients' function was returned within three weeks and the remaining $15 \%$ after three to five months [20]. The exact reason for the delayed return to function in the latter group is still not clear, but there is a suggestion that the presence of facial nerve enhancement on MRI may be associated with a longer duration of symptom. Our patient had positive MRI enhancement and received a course of steroid and valacyclovir, and at his three-month follow-up visit, he had only mild facial weakness.

\section{Conclusions}

Facial nerve palsy can be seen any time during the course of COVID-19 infection and can sometimes present as late as one month after diagnosis. So far, we believe its association with COVID-19 is more than just a mere coincidence but one of the emerging manifestations of this novel virus. Clinicians should consider this as a potential neurologic complication when managing patients with COVID-19 infection and start treatment early when present, as they would in other causes of Bell's palsy.

\section{Additional Information}

\section{Disclosures}

Human subjects: Consent was obtained or waived by all participants in this study. Conflicts of interest: In compliance with the ICMJE uniform disclosure form, all authors declare the following: Payment/services info: All authors have declared that no financial support was received from any organization for the submitted work. Financial relationships: All authors have declared that they have no financial relationships at present or within the previous three years with any organizations that might have an interest in the submitted work. Other relationships: All authors have declared that there are no other relationships or activities that could appear to have influenced the submitted work.

\section{References}

1. Zandian A, Osiro S, Hudson R, Ali I, Matusz P, Tubbs S, Loukas M: The neurologist's dilemma: a comprehensive clinical review of Bell's palsy, with emphasis on current management trends. Med Sci Monit. 2014, 20:83-90. 10.12659/MSM.889876

2. Tai W, He L, Zhang X, et al.: Characterization of the receptor-binding domain (RBD) of 2019 novel coronavirus: implication for development of RBD protein as a viral attachment inhibitor and vaccine. Cell Mol Immunol. 2020, 17:613-620. 10.1038/s41423-020-0400-4

3. Baig AM, Khaleeq A, Ali U, Hira S: Evidence of the COVID-19 virus targeting the CNS: tissue distribution, host-virus interaction, and proposed neurotropic mechanisms. ACS Chem Neurosci. 2020, 1:995-998. 10.1021/acschemneuro.0c00122

4. Dubé M, Le Coupanec A, Wong AHM, Rini JM, Desforges M, Talbot PJ: Axonal transport enables neuron-toneuron propagation of human coronavirus OC43. J Virol. 2018, 92:1-21. 10.1128/JVI.00404-18

5. Lima MA, Silva MTT, Soares CN, et al.: Peripheral facial nerve palsy associated with COVID-19. J. Neurovirol. 2020, 26:941-944. 10.1007/s13365-020-00912-6

6. Zhang W, Xu L, Luo T, Wu F, Zhao B, Li X: The etiology of Bell's palsy: a review . J Neurol. 2020, 267:18961905. 10.1007/s00415-019-09282-4

7. Zammit M, Markey A, Webb C: A rise in facial nerve palsies during the coronavirus disease 2019 pandemic . I Laryngol Otol. 2020, 134:905-908. 10.1017/S0022215120002121

8. Codeluppi L, Venturelli F, Rossi J, et al.: Facial palsy during the COVID-19 pandemic. Brain Behav. 2021, 11:01939. 10.1002/brb3.1939

9. Theophanous C, Santoro J, Itani R: Bell's palsy in a pediatric patient with hyper IgM syndrome and severe acute respiratory syndrome coronavirus 2 (SARS-Cov-2). Brain Dev. 2020, 387:1016-2020. 10.1016/j.braindev.2020.08.017

10. Wan Y, Cao S, Fang Q, Wang M, Huang Y: Coronavirus disease 2019 complicated with Bell's palsy: a case report [PREPRINT]. Research Square. 2020, 10.21203/rs.3.rs-23216/v1

11. Figueiredo R, Falcao V, Pinto MJ, Ramalho C: Peripheral facial paralysis as presenting symptom of COVID19 in a pregnant woman. BMJ Case Rep. 2020, 13:237146. 10.1136/bcr-2020-237146

12. Mehta S, Mackinnon D, Gupta S: Severe acute respiratory syndrome coronavirus 2 as an atypical cause of Bell's palsy in a patient experiencing homelessness. CJEM. 2020, 22:608-610. 10.1017/cem.2020.418

13. Goh Y, Beh D, Makmur A, Somani J, Chan C: Pearls \& Oy-sters: Facial nerve palsy as a neurological manifestation of Covid-19 infection. Neurology. 2020, 95:364-367. 10.1212/WNL.0000000000009863

14. Chen $\mathrm{T}, \mathrm{Wu} \mathrm{D}$, Chen $\mathrm{H}$, et al.: Clinical characteristics of 113 deceased patients with coronavirus disease 2019: retrospective study. BMI. 2000, 26:1091-1010. 10.1136/bmi.m1091

15. Zhao H, Shen D, Zhou H, Liu J, Chen S: Guillain-Barré syndrome associated with SARS-CoV-2 infection: 


\section{Cureus}

causality or coincidence?. Lancet Neurol. 2020, 19:383-384. 10.1016/S1474-4422(20)30109-5

16. Gutiérrez-Ortiz C, Méndez A, Rodrigo-Rey S, et al.: Miller Fisher syndrome and polyneuritis cranialis in COVID-19. Neurology. 2020, 95:601-605. 10.1212/wnl.0000000000009619

17. Zahra SA, Iddawela S, Pillai K, Choudhury RY, Harky A: Can symptoms of anosmia and dysgeusia be diagnostic for COVID-19?. Brain Behav. 2020, 10:01839. 10.1002/brb3.1839

18. Khaja M, Gomez GPR, Santana Y, Hernandez N, Haider A, Lara J, Elkin R: A 44-year-old Hispanic man with loss of taste and bilateral facial weakness diagnosed with Guillain-Barre syndrome and Bell's palsy associated with SARS-Cov-2 infection treated with intravenous immunoglobulin. Am J Case Rep. 2020, 21:927956. 10.12659/AJCR.927956

19. Quant EC, Jeste SS, Muni RH, Cape AV, Bhussar MK, Peleg AY: The benefits of steroid versus steroids plus antivirals for treatment of Bell's palsy: a meta-analysis. BMJ. 2009, 339:3354. 10.1136/bmj.b3354

20. Peitersen E: Bell's palsy: the spontaneous course of 2,500 peripheral facial Nerve palsies of different etiologies. Acta Oto-Laryngologica. 2002, 122:4-30. 10.1080/000164802760370736 